\title{
The Peptide Antibiotic Clavanin A Interacts Strongly and Specifically with Lipid Bilayers $^{\dagger}$
}

\author{
Ellen J. M. van Kan,,$\S$ Dragomir N. Ganchev, ${ }^{\S, \|}$ Margot M. E. Snel," Vladimir Chupin,,$^{\S}$ Arie van der Bent,, and \\ Ben de Kruijff*, $\S$ \\ Department of Functional Ingredients, Food and Food Processing, Agrotechnological Research Institute, Wageningen \\ University and Research Centre, Bornsesteeg 59, 6708 PD Wageningen, The Netherlands, and Department of Physical \\ Chemistry of Interfaces, Debye Institute, and Department of Biochemistry of Membranes, Centre for Biomembranes and Lipid \\ Enzymology, Institute of Biomembranes, Utrecht University, Padualaan 8, 3584 CH Utrecht, The Netherlands
}

Received May 28, 2003; Revised Manuscript Received July 18, 2003

\begin{abstract}
In this study the interaction of the antimicrobial peptide clavanin A with phosphatidylcholine bilayers is investigated by DSC, NMR, and AFM techniques. It is shown that the peptide interacts strongly and specifically with the lipids, resulting in increased order-disorder phase transition temperatures, phase separation, altered acyl chain and headgroup packing, and a drastically changed surface morphology of the bilayer. These results are interpreted in terms of clavanin-specific interactions with lipids and are discussed in the light of the different mechanisms by which clavanin A can destroy the barrier function of biological membranes.
\end{abstract}

The clavanins belong to a family of antimicrobial peptides that are expressed in the hemocytes of the marine organism Styela clava (1-3). These peptides exhibit broad-spectrum antimicrobial activities against Gram-positive and Gramnegative bacteria, as well as several fungi $(1,2)$. Similar to many other naturally occurring peptide antibiotics $(4-10)$, the clavanins exert their antimicrobial effect via permeabilization of the target membranes $(11-13)$. Clavanins are cationic, amphipathic peptides that consist of 23 amino acids. They are remarkably rich in glycines, histidines, and phenylalanines, as is seen from the primary structure of clavanin A (VFQFLGKIIHHVGNFVHGFSHVF- $\mathrm{NH}_{2}$ ). The Gly, His, and Phe residues play important roles in the antimicrobial actions of wild-type clavanin A (12-14).

In contrast to most membrane-active peptide antibiotics wild-type clavanin A has been shown to use distinct modes of pH-dependent action to permeabilize target membranes (13). At neutral $\mathrm{pH}$, bacterial membranes and lipid vesicles are disrupted in a nonspecific manner $(12,13)$. Under acidic conditions, the peptide becomes highly positively charged, due to protonation of the four histidines within the clavanin A sequence. In this state the peptide has a 10-fold increased antimicrobial activity, which is accompanied by selective membrane permeabilization to protons. This presumably is due to specific interactions of clavanin A with membrane proteins that are involved in generating transmembrane ion gradients (13). Strikingly, at low $\mathrm{pH}$ no permeabilization of

$\dagger$ This study has been carried out with financial support from the Commission of the European Communities, Agriculture and Fisheries (FAIR) specific RTD program, CT97-3135, and the Division of Chemical Sciences of NWO.

* Corresponding author. Tel: +31 30 2531607. Fax: +31 30 2539171. E-mail: b.dekruijff@chem.uu.nl.

Agrotechnological Research Institute (WUR).

$\S$ Department of Biochemistry of Membranes (UU).

" Department of Physical Chemistry of Interfaces (UU). the bilayer of lipid vesicles occurs despite the ability of the peptide to efficiently interact with and insert into model membranes under these conditions (13). Studies on other histidine-rich amphipathic peptides demonstrated that $\mathrm{pH}$ may trigger changes in membrane topology of the peptide $(15,16)$, which could apply for clavanin as well. The lack of distinct conformational preferences induced by Gly and Phe was shown to be important for the membrane activities of clavanin A $(12,14)$. Clavanin A thus appears to be a special antimicrobial peptide with high membrane affinity and a mode of action that is triggered by the $\mathrm{pH}$ and involves both membrane lipids and membrane proteins.

Virtually nothing is known about the effect of clavanin A on the organization of membrane lipids. Yet, changes in lipid organization likely play a role in the mechanisms of clavanin $\mathrm{A}$ as suggested for other antimicrobial peptides (17-22).

Therefore, in this study we analyzed the effect of clavanin A on the thermotropic properties, the molecular organization and dynamics, and supramolecular organization of 1,2dipalmitoyl-sn-glycero-3-phosphocholine (DPPC) ${ }^{1}$ bilayers using DSC, NMR, and AFM techniques, respectively. DPPC was chosen as the test lipid because (1) its properties are well understood, (2) clavanin interacts with this lipid in a comparable way as with bacterial lipids (12), and (3) this lipid allows all three techniques to be applied in a comparable fashion, yielding an integrated view on clavanin-lipid interaction. The results show that clavanin $\mathrm{A}$ interacts in a

\footnotetext{
${ }^{1}$ Abbreviations: AFM, atomic force microscopy; DMPC, 1,2dimyristoyl-sn-glycero-3-phosphocholine; DPPC, 1,2-dipalmitoyl-snglycero-3-phosphocholine; DSC, differential scanning calorimetry; ESMS, electron spray mass spectrometry; Fmoc, 9-fluorenylmethoxycarbonyl; $\mathrm{L}_{\alpha}$ phase, liquid-crystalline phase; $\mathrm{L}_{\beta}$ phase, gel phase; MES, 2-( $N$-morpholino)ethanesulfonic acid; NMR, nuclear magnetic resonance; RP-HPLC, reversed-phase high-performance liquid chromatography; SUV, small unilamellar vesicle; TFE, trifluoroethanol; Tris, tris(hydroxymethyl)aminomethane.
} 
specific way with DPPC bilayers, which leads to new insights into the mode of action of the peptide.

\section{EXPERIMENTAL PROCEDURES}

Materials. $N$ - $\alpha$-Fmoc-protected amino acids, coupling reagent, and resin used in peptide synthesis were purchased from Novabiochem (Läufelfingen, Switzerland). Solvents for peptide synthesis and HPLC were obtained from Biosolve (Valkenswaard, The Netherlands). 1,2-Dipalmitoyl-sn-glycero-3-phosphocholine (DPPC) and 1,2-dimyristoyl-sn-glycero-3-phosphocholine (DMPC) were purchased from Avanti Polar Lipids, Inc. (Alabaster, AL), and used without further purification. Acyl chain perdeuterated DPPC- $d_{62}$ was purchased from Cambridge Isotope Laboratories, Inc. (Andover, MA). All other chemicals used were of analytical or reagent grade.

Peptide Synthesis and Purification. Clavanin A and the mutant peptide $5 \mathrm{~W}$ in which the five phenylalanines were replaced by tryptophans were prepared using automated solid-phase peptide synthesis and purified using RP-HPLC on a Waters symmetry C18 column (Milford, MA), as previously described $(12,13)$. Via analytical RP-HPLC (12) and electron spray mass spectrometry (ES-MS) the peptides' purities and molecular masses were determined to confirm their composition.

Sample Preparation. The peptides were dissolved in TFE and added to DPPC or DPPC- $d_{62}$ dissolved in a mixture of chloroform and methanol $(3: 1 \mathrm{v} / \mathrm{v})$ to the desired peptide/ lipid ratio. These mixtures were dried in a rotary evaporator, followed by overnight storage under high vacuum. The dried mixed films were dispersed in either $10 \mathrm{mM}$ Tris- $\mathrm{HCl}, \mathrm{pH}$ 7.0 , or $10 \mathrm{mM} \mathrm{MES} / \mathrm{NaOH}$, pH 5.5, to obtain a lipid concentration of $5 \mathrm{mM}$ (for DSC and NMR) or $1 \mathrm{mM}$ (for AFM) determined as inorganic phosphorus (23). For NMR deuterium-depleted water was used. To further homogenize the sample for DSC and NMR, the lipid dispersions were vortexed at $50{ }^{\circ} \mathrm{C}$ (at $10{ }^{\circ} \mathrm{C}$ above the main phase transition temperature), followed by two freeze-thaw cycles. For analysis by AFM the lipid dispersions were freeze-thawed 10 times, followed by bath sonication and ultracentrifugation as described before (24).

Differential Scanning Calorimetry. Thermograms of 0.5 $\mathrm{mL}$ lipid dispersions (degassed prior to the measurements) were recorded on a Microcal MCS calorimeter (Northampton, MA) scanning at a rate of $60{ }^{\circ} \mathrm{C} / \mathrm{h}$. Reproducible thermograms were obtained in two or three heating and cooling cycles. The DSC scans were analyzed using the Origin software package from Microcal Inc.

NMR Measurements. NMR spectra were recorded on samples pelleted prior to use on an Avance $500 \mathrm{WB}$ spectrometer. ${ }^{2} \mathrm{H}$ NMR spectra were obtained using a quadrupolar echo technique (25). The recycling delay was $1 \mathrm{~s} .{ }^{31} \mathrm{P}$ NMR spectra were recorded using a high-resolution $10 \mathrm{~mm}$ broad-band probe with broad-band gated proton decoupling. The recycling delay was $1.5 \mathrm{~s}$ and the $\pi / 4$ pulse width $7 \mu \mathrm{s}$. An exponential multiplication with a line broadening factor of $100 \mathrm{~Hz}$ was used before performing the Fourier transformation. Chemical shifts in ${ }^{31} \mathrm{P}$ NMR spectra were measured relative to the signal originating from isotropically moving phospholipids.

Atomic Force Microscopy. Supported lipid/peptide bilayers were prepared using the vesicle fusion method (26). The SUV suspension $(75 \mu \mathrm{L})$ was deposited onto freshly cleaved mica (10 $\mathrm{mm}$ diameter). The vesicles were allowed to adsorb and fuse on the mica for $1 \mathrm{~h}$ at room temperature. Subsequently, the sample was rinsed three times with $75 \mu \mathrm{L}$ of Tris buffer and heated for $1 \mathrm{~h}$ at $65^{\circ} \mathrm{C}$. After being cooled to room temperature, the sample was rinsed again with $75 \mu \mathrm{L}$ of Tris buffer (three times). The supported bilayers were investigated using AFM in a buffer environment. The samples were mounted on an E-scanner, which was calibrated on a standard grid of a Nanoscope III AFM (Digital Instruments, Santa Barbara, CA). A fluid cell without O-ring was fitted, and the sample was scanned in contact mode, using oxidesharpened $\mathrm{Si}_{3} \mathrm{~N}_{4}$ tips attached to a triangular cantilever with a spring constant of $0.06 \mathrm{~N} / \mathrm{m}$ (NanoProbe; Digital Instruments, Santa Barbara, CA). All images were recorded at a minimal force $(<500 \mathrm{pN})$ where the scans were stable and clear and at temperatures between 24 and $28^{\circ} \mathrm{C}$. All images shown are flattened raw data.

\section{RESULTS}

Differential Scanning Calorimetry. The effect of wild-type clavanin A on the thermotropic phase transition behavior of DPPC dispersions was investigated using DSC. Figure 1A displays the phase transition behavior of DPPC in the absence and presence of wild-type clavanin $\mathrm{A}$ at neutral $\mathrm{pH}$. The thermogram of pure DPPC visualizes the pretransition around $35{ }^{\circ} \mathrm{C}$ and the main or chain-melting transition at $41{ }^{\circ} \mathrm{C}$. Already at $1 \mathrm{~mol} \%$, clavanin A eliminates the pretransition and moves the chain-melting transition peak to slightly higher $\left(\sim 1^{\circ} \mathrm{C}\right)$ temperatures. A higher clavanin concentration leads to a slightly further increase in the main transition temperature and the appearance of an additional transition at 47 ${ }^{\circ} \mathrm{C}$. At a peptide concentration of $10 \mathrm{~mol} \%$ the main transition peak moves back to its original position, and an additional, partial overlapping peak with a transition temperature centered around $43{ }^{\circ} \mathrm{C}$ is present. This is paralleled by an increased total chain melting enthalpy from 8.6 (pure DPPC) to $11.1 \mathrm{kcal} / \mathrm{mol}$ for the $10 \%$ clavanin A sample. The high-temperature peaks must originate from DPPC, as control measurements on the pure peptide do not show these transitions (not shown). These clavanin-induced high-temperature transitions are highly unusual, as generally peptides and proteins display the opposite behavior $(17,27-29)$, i.e., lowering of the transition temperature and a decrease in transition enthalpy. Such behavior is shown in Figure 1B for the mutant peptide $5 \mathrm{~W}$, in which the five phenylalanines were replaced by tryptophans. The $5 \mathrm{~W}$ peptide eliminates the pretransition at low concentration and causes a slight increase in the main transition temperature at 1 and $2 \mathrm{~mol}$ $\%$. However, at 4 and $10 \mathrm{~mol} \%$ peptide $5 \mathrm{~W}$ the transition temperature is strongly reduced. The peak is broadened which is accompanied by reductions in transition enthalpies to 7.4 and $5.6 \mathrm{kcal} / \mathrm{mol}$ at peptide molar ratios of 0.04 and 0.1 , respectively (not shown). This classical behavior is typical for peptides that insert between the acyl chains and thereby interfere with the cooperative chain transition.

The striking difference in effect of clavanin A and the $5 \mathrm{~W}$ mutant on the chain melting transition of DPPC demonstrates a pronounced specificity of the peptide-lipid interaction of the native molecule. At $\mathrm{pH}$ 5.5, the clavanin A-DPPC dispersions display thermograms very similar to those observed under neutral conditions (not shown). This 

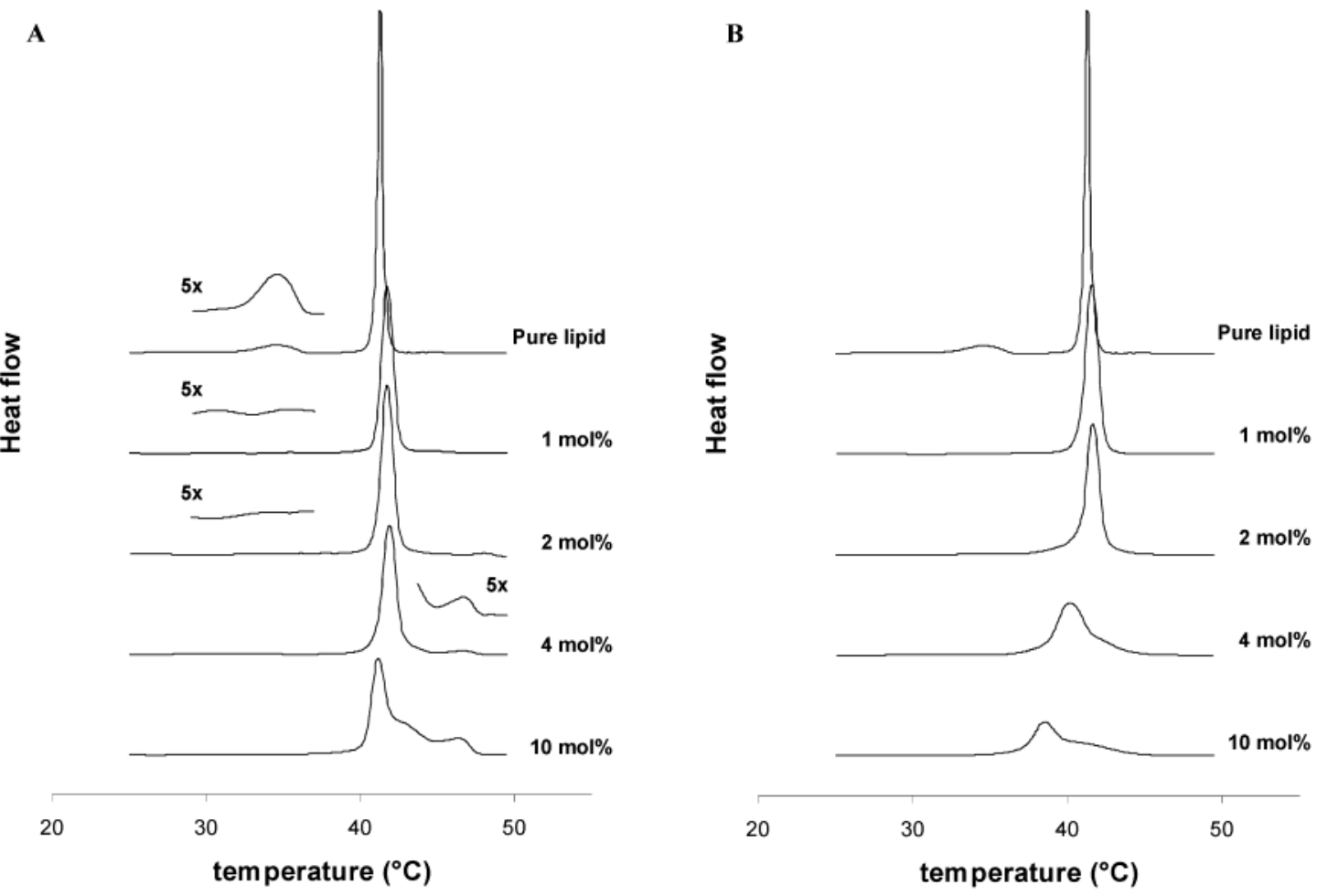

FIGURE 1: DSC thermograms of DPPC and clavanin A (A) or $5 \mathrm{~W}$ mutant-DPPC mixtures (B) at the indicated peptide molar ratios (pH 7.0, $10 \mathrm{mM}$ Tris- $\mathrm{HCl}$ buffer). The pretransition temperature region and high-temperature transition region have been enlarged $(5 \times)$ for the pure lipid, $1 \mathrm{~mol} \%, 2 \mathrm{~mol} \%$, and $4 \mathrm{~mol} \%$ clavanin A-DPPC samples, respectively.

indicates that protonation of the histidine residues does not influence the effect of the peptide on the phase behavior of DPPC despite the large difference in mode of action at the different pHs. Similar results were observed for DMPC, i.e., peptide-induced higher melting transitions (not shown), demonstrating the generality of the effect of clavanin A on the phase behavior of PC. The occurrence of high-temperature transitions and high transition enthalpies at high peptide concentrations (Figure 1A) suggests clavanin A to affect the ordering of the phospholipid acyl chains and induce phase separation. To obtain insight into the molecular origin of these effects, NMR studies were undertaken on the clavanin A-DPPC system. Given the similarity in effect at neutral and acidic $\mathrm{pH}$ values, further studies were restricted to samples at neutral $\mathrm{pH}$.

NMR Spectroscopy. Samples were prepared using acyl chain perdeuterated DPPC- $d_{62}$, enabling assessment of the headgroup region by ${ }^{31} \mathrm{P}$ NMR and the chain region by ${ }^{2} \mathrm{H}$ NMR.

${ }^{31} \mathrm{P}$ NMR of phospholipid dispersions gives both information on the local order and mobility of the phosphate part of the lipid headgroup and the overall organization of the aggregate structure in which the phospholipid resides $(30$, 31 ). Figure 2 shows a selection of ${ }^{31} \mathrm{P}$ NMR spectra of the various samples investigated in $2{ }^{\circ} \mathrm{C}$ steps in the $30-60{ }^{\circ} \mathrm{C}$ temperature range. The spectra shown were recorded at 42 ${ }^{\circ} \mathrm{C}$, which is well above the chain melting transition of pure DPPC, because perdeuteration decreases the main transition temperature by $5{ }^{\circ} \mathrm{C}(32)$. In the absence of peptide, the spectrum shows the line shape characteristic for lipids, organized in extended bilayers in the disordered $\mathrm{L}_{\alpha}$ phase with a high-field and a low-field shoulder separated by $\sim 47$ ppm, reflecting the residual chemical shift anisotropy. In the presence of 4 or $10 \mathrm{~mol} \%$ clavanin A, this overall line shape

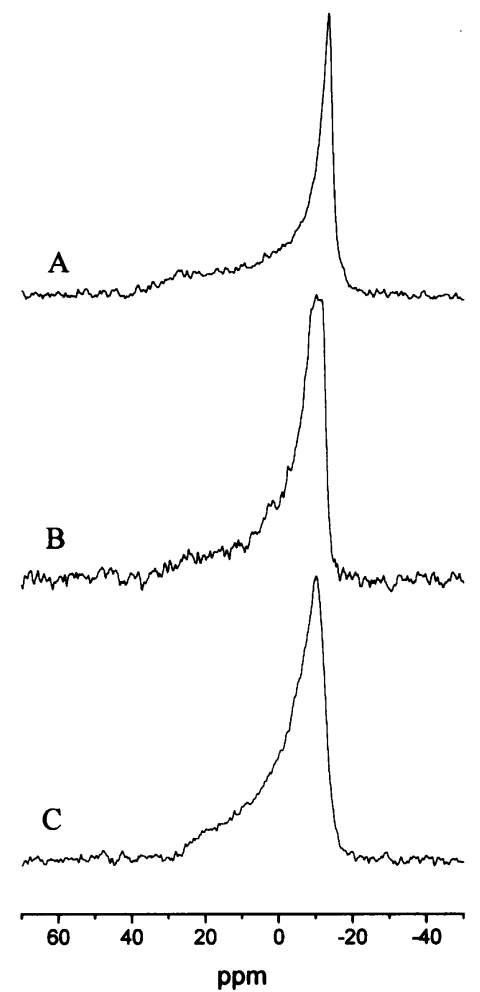

FIGURE 2: ${ }^{31} \mathrm{P}$ NMR spectra of DPPC- $d_{62}$ in the absence (A) and in the presence of $4 \mathrm{~mol} \%$ (B) and $10 \mathrm{~mol} \%$ (C) clavanin at 42 ${ }^{\circ} \mathrm{C}(\mathrm{pH}$ 7.0, $10 \mathrm{mM}$ Tris-HCl buffer).

is maintained, demonstrating that all DPPC remains organized in extended bilayers despite the presence of high concentrations of clavanin A. No isotropic signals were observed. However, the line broadening and reduction of the chemical shift anisotropy to $40 \mathrm{ppm}$ at $10 \%$ clavanin are some noticeable changes in the spectra. This behavior most 

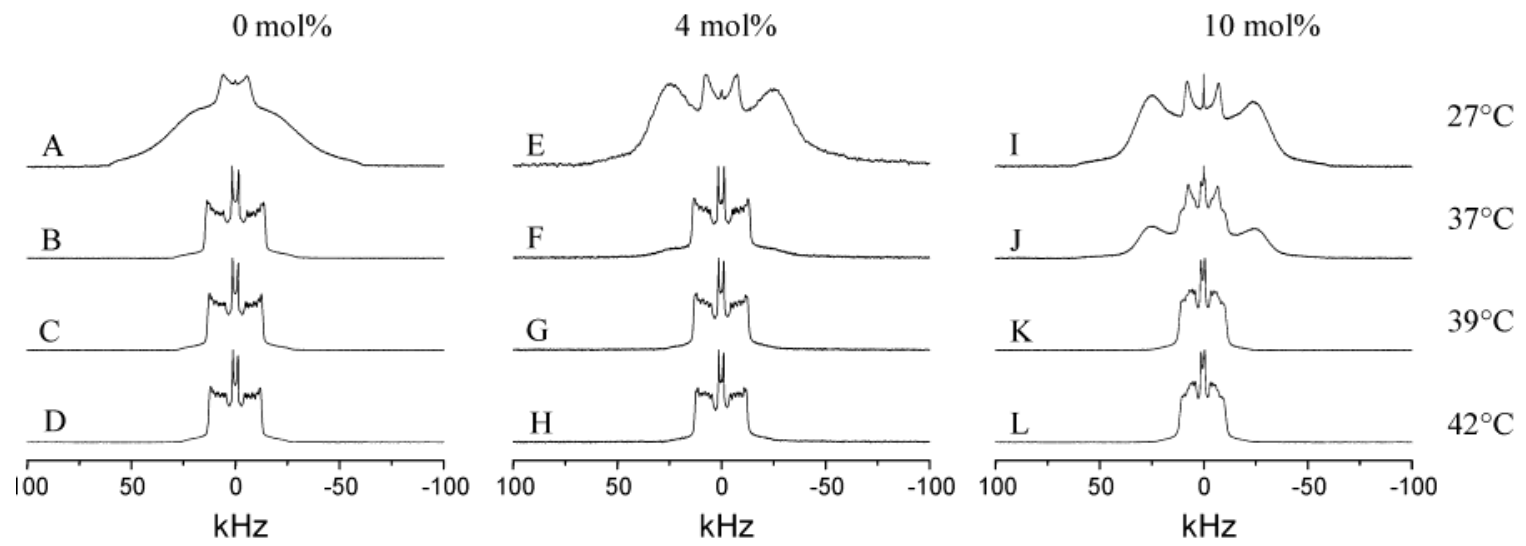

FIGURE 3: ${ }^{2} \mathrm{H}$ NMR spectra of DPPC- $d_{62}$ in the absence $(\mathrm{A}-\mathrm{D})$ and in the presence of $4 \mathrm{~mol} \%(\mathrm{E}-\mathrm{H})$ and $10 \mathrm{~mol} \%$ (I-L) clavanin at different temperatures ( $\mathrm{pH} 7.0,10 \mathrm{mM}$ Tris- $\mathrm{HCl}$ buffer): (A, E, I) $27{ }^{\circ} \mathrm{C} ;(\mathrm{B}, \mathrm{F}, \mathrm{J}) 37^{\circ} \mathrm{C} ;(\mathrm{C}, \mathrm{G}, \mathrm{K}) 39^{\circ} \mathrm{C} ;(\mathrm{D}, \mathrm{H}, \mathrm{L}) 42{ }^{\circ} \mathrm{C}$.

likely originates from increased motional freedom of the headgroup due to the presence of the peptide. These effects were observed at all temperatures above the chain melting transition. Below the main phase transition broadened gel state ${ }^{31} \mathrm{P}$ NMR line shapes were observed with no clear effects of clavanin (not shown). No multicomponent spectra, indicative of phase separation, were observed.

${ }^{2} \mathrm{H}$ NMR on chain deuterium labeled lipids provides a more sensitive and detailed view on the effect of clavanin on acyl chain order and dynamics. Perdeuterated DPPC was employed to obtain information on the entire acyl chains, and spectra were recorded in $2{ }^{\circ} \mathrm{C}$ steps over the $26-65^{\circ} \mathrm{C}$ temperature range. Figure 3 presents a selection of spectra for DPPC in the absence $(A-D)$ and presence of $4(E-H)$ and $10(\mathrm{I}-\mathrm{L}) \mathrm{mol} \%$ clavanin. Spectrum A recorded for DPPC at $27{ }^{\circ} \mathrm{C}$ is a typical gel state spectrum with a broad featureless line shape originating from the acyl chains whose motions are severely restricted. On top of the spectrum a broad doublet of the terminal $-\mathrm{CD}_{3}$ resonances is noticed. This line shape is understood in terms of a two-step rotational jump model $(32,33)$. At $37{ }^{\circ} \mathrm{C}$ (corresponds to $41^{\circ} \mathrm{C}$ for nondeuterated DPPC) the acyl chains are largely melted as demonstrated by the narrowed line shape, which consists of a series of overlapping doublets, originating from the different $-\mathrm{CD}_{2}$ groups and characteristic of the $\mathrm{L}_{\alpha}$ phase in which the acyl chains have considerable motional freedom. The most outer spectral feature originates from the methylenes closest to the headgroup which have the least motional freedom. Further increase of the temperature to $42{ }^{\circ} \mathrm{C}$ (spectra $\mathrm{B}-\mathrm{D}$ ) does not largely affect the line shape. The sharp central doublet comes from the $-\mathrm{CD}_{3}$ groups which have most motional freedom.

First, the results of $10 \mathrm{~mol} \%$ clavanin (spectra I-L) will be described, because these spectra showed the strongest effects and will serve as a frame of reference to describe the intermediate spectra $(\mathrm{E}-\mathrm{H})$ recorded for the $4 \mathrm{~mol} \%$ clavanin sample. From the spectra it is evident that clavanin at all temperatures affects the acyl chains. Under gel state conditions (compare spectrum A with spectrum I) the broad spectral component from the $-\mathrm{CD}_{2}$ groups is narrowed and shows a defined "doublet" structure. The same can be concluded for the $-\mathrm{CD}_{3}$ resonances. This demonstrates that clavanin interacts with DPPC in the gel state and increases the motional freedom of the acyl chains, however, not to the level of the $\mathrm{L}_{\alpha}$ phase. Comparing spectra $\mathrm{B}$ and $\mathrm{J}$, recorded at $37{ }^{\circ} \mathrm{C}$, immediately shows that clavanin increases the phase transition temperature of part of the PC molecules. In the presence of clavanin a substantial amount of lipid still shows the overall gel state characteristics, whereas in its absence this is not the case. This is in full agreement with the DSC data and shows the occurrence of phase separation. Moreover, the broad component spectrum 3J shows three additional features. These could be identified (from out to in) as the outmost $-\mathrm{CD}_{2}$ resonance of part of the lipids in the $\mathrm{L}_{\alpha}$ phase lipids, the doublet of the $-\mathrm{CD}_{3}$ resonance of the gel state part of the spectrum, and a narrow doublet of the $-\mathrm{CD}_{3}$ resonance of the $\mathrm{L}_{\alpha}$ phase lipids. Further increase of the temperature of the $10 \mathrm{~mol} \%$ clavanin sample to 42 ${ }^{\circ} \mathrm{C}$ (spectra $\mathrm{K}-\mathrm{L}$ ) shows melting of the remaining gel state lipid and the occurrence of a line shape which resembles that of the $\mathrm{L}_{\alpha}$ phase of the pure lipid (spectra $\mathrm{C}$ and $\mathrm{D}$ ). This line shape, however, is narrowed as witnessed from the decreased outer splitting of the most immobilized $-\mathrm{CD}_{2}$ 's and the reduced quadrupolar splitting of the $-\mathrm{CD}_{3}$ from 3 to $2 \mathrm{kHz}$ at $42{ }^{\circ} \mathrm{C}$. The spectrum at $42^{\circ} \mathrm{C}$ (and higher) shows no signs of more than one type of lipid organization, which suggests that clavanin now interacts with all DPPC molecules in a similar fashion. All spectra of the 4 mol \% clavanin samples $(\mathrm{E}-\mathrm{H})$ show intermediate behavior, demonstrating the clavanin concentration dependency of the observed effects. The line shapes under fully melted conditions of the samples can be readily qualitatively related (Figure 4 ). This figure shows the expanded spectra of the $42{ }^{\circ} \mathrm{C}$ samples (AC) and compares them to the spectrum of the pure DPPC sample at $65{ }^{\circ} \mathrm{C}$ (D). The spectral resemblance of the 10 mol \% sample at $42{ }^{\circ} \mathrm{C}$ (C) and that of DPPC at $65{ }^{\circ} \mathrm{C}$ strongly suggests that the increased motional freedom induced by $10 \mathrm{~mol} \%$ clavanin is equivalent to a $23{ }^{\circ} \mathrm{C}$ increase in temperature in the $\mathrm{L}_{\alpha}$ phase.

$A F M$. AFM can be used to inspect the surface morphology of supported gel state DPPC bilayers containing peptides and has revealed the occurrence of several types of distinct morphologies induced by transmembrane $\alpha$-helical peptides $(24,29)$.

It was investigated whether clavanin, which can disrupt lipid bilayers in a nonspecific manner, would cause a change in organization of the lipid bilayer. Figure $5 \mathrm{~A}$ shows an AFM image of pure DPPC bilayers deposited on mica via the vesicle fusion method. To be able to directly compare the results to that obtained with the other techniques, the samples 


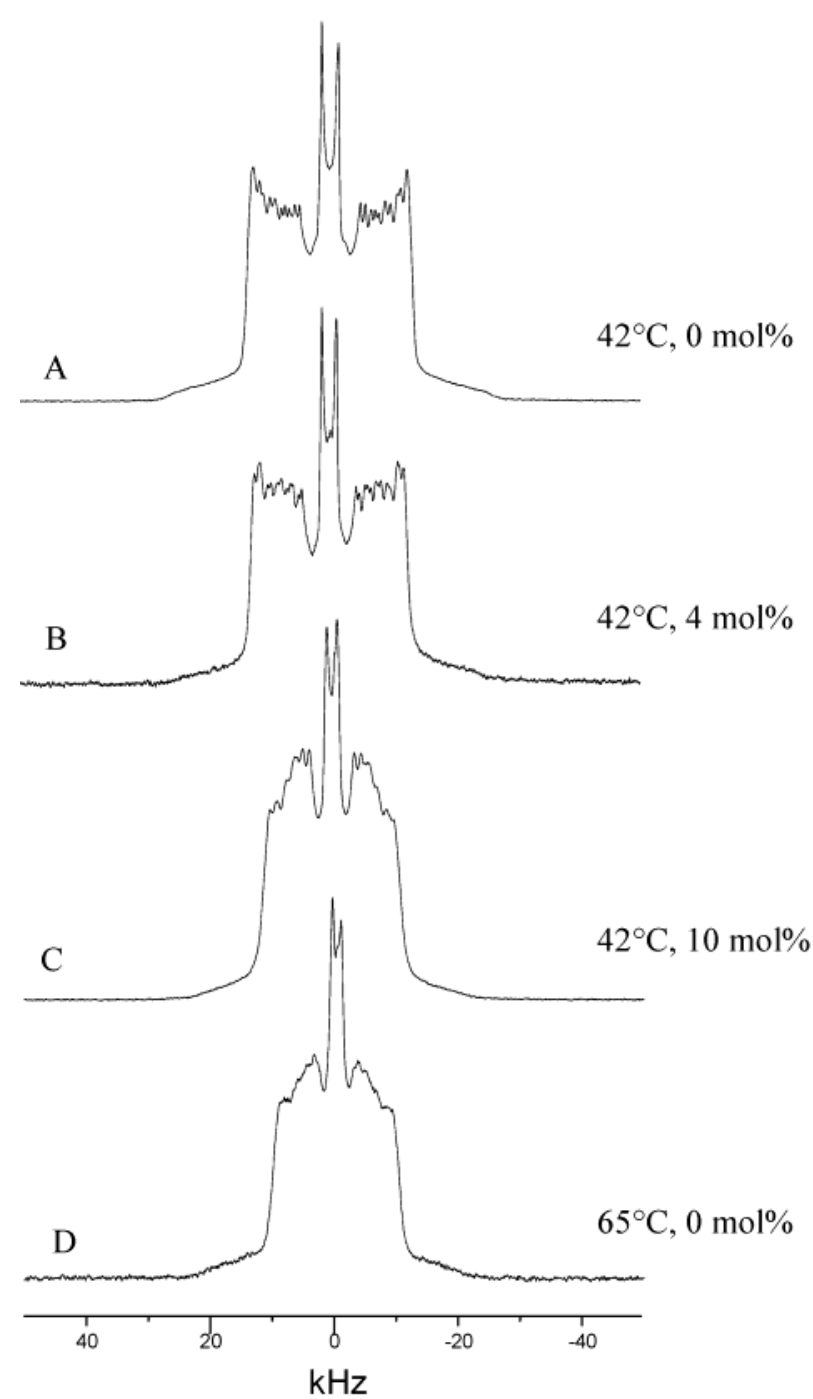

FIGURE 4: ${ }^{2} \mathrm{H}$ NMR spectra of DPPC- $d_{62}$ in the absence (A, D) and in the presence of $4 \mathrm{~mol} \%$ (B) and $10 \mathrm{~mol} \%$ (C) clavanin (pH 7.0, $10 \mathrm{mM}$ Tris- $\mathrm{HCl}$ buffer). Spectra $\mathrm{A}-\mathrm{C}$ were recorded at $42{ }^{\circ} \mathrm{C}$, and spectrum $\mathrm{D}$ was recorded at $65^{\circ} \mathrm{C}$.

were prepared and analyzed in $10 \mathrm{mM}$ Tris- $\mathrm{HCl}, \mathrm{pH} 7$, buffer. The picture shows the dark surface of the DPPC bilayer with an expected $(24,34,35)$ thickness of $6 \mathrm{~nm}$ (measured from a defect present in the bilayer). On top of the bilayer many light patches were present with heights varying between 30 and $50 \mathrm{~nm}$. These are most likely unopened vesicles lying on the supported bilayer, because scanning at higher forces results in flattening of these structures (not shown). These images differ from those observed in the presence of $20 \mathrm{mM} \mathrm{NaCl}$, which reveal smooth supported bilayers $(24,29)$ (data not shown) and suggest that the Tris buffer somewhat influences the vesicle adsorption and fusion process.

Figure 5B shows a representative picture of a $4 \mathrm{~mol} \%$ clavanin A containing sample which displays a completely different morphology. No unopened vesicles are present anymore, demonstrating that clavanin facilitates the vesicle fusion process. More important, the morphology of the bilayer is largely affected. The light surface represents the bilayer which is now studded with regularly distributed pointlike defects (dark areas). The large square defect in the middle of the picture is artificially produced to confirm the presence of a bilayer on the mica support.
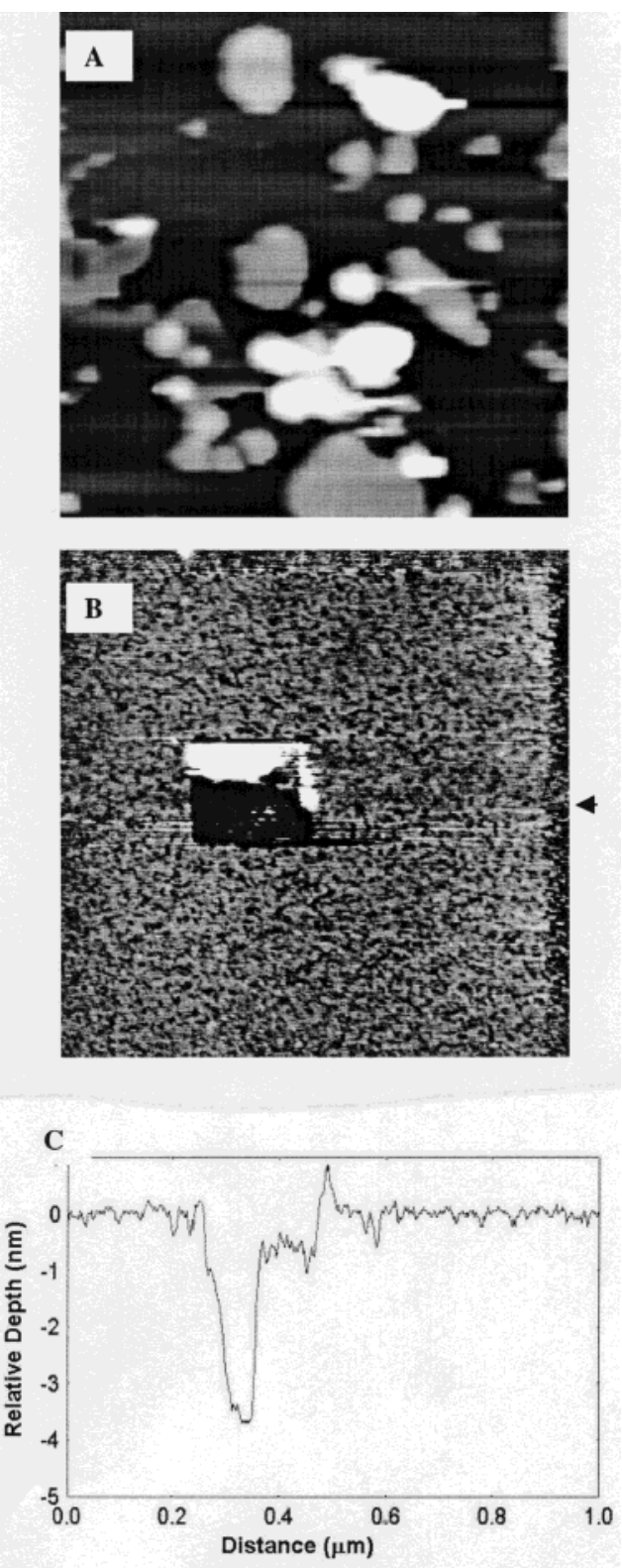

FIGURE 5: (A) AFM image of a DPPC supported bilayer in 10 $\mathrm{mM}$ Tris-HCl buffer ( $\mathrm{pH}$ 7). (B) Image of a bilayer from DPPC containing $4 \mathrm{~mol} \%$ WT clavanin in $10 \mathrm{mM}$ Tris- $\mathrm{HCl}$ buffer $(\mathrm{pH}$ 7). The scan size of image A and B is $1 \times 1 \mu \mathrm{m}$, and the $Z$-scale is $30 \mathrm{~nm}$. (C) Height profile across the image (at the arrow) shown in panel $\mathrm{B}$.

The presence of 4 mol \% clavanin causes the bilayer to thin. This can be deduced from the height profile shown in Figure 5C. The surface of the DPPC/clavanin A bilayer is now 3-4 $\mathrm{nm}$ above the mica, which is approximately $2 \mathrm{~nm}$ lower than that of DPPC, corresponding to a decrease in thickness of the supported bilayer from 6 to $3-4 \mathrm{~nm}$. This thinning effect is in agreement with the "fluidizing" effect of the peptide under gel state conditions as observed by NMR. The pointlike depressions indicate phase separation in peptide-rich and peptide-poor domains in accordance with the DSC results. The carpet-like appearance of the bilayer directly suggests an overall strong destabilization of the lipid bilayer consistent with the proposed mode of action of the peptide. At higher peptide concentration the overall morphology of the bilayer was found to be similar (not shown). 


\section{DISCUSSION}

The results of this study demonstrate that the peptide antibiotic clavanin A interacts strongly and in a special way with phosphatidylcholine bilayers. First, the various aspects of the clavanin-DPPC interactions will be discussed. Subsequently, these observations will be viewed in the light of the peptide's antimicrobial activity.

The most striking effect observed in both DSC and NMR studies is the occurrence of peptide-induced high-temperature order-disorder transitions in the bilayer. This implies phase separation into peptide-rich and peptide-poor domains. In the peptide-rich domains clavanin stabilizes the gel state up to $6^{\circ} \mathrm{C}$ as the highest melting transition occurs around 47 ${ }^{\circ} \mathrm{C}$. This is an unusual effect of a peptide, which normally lowers the phase transition temperature as it intercalates between the lipid headgroups. Increased phase transition temperatures can be caused by different mechanisms. Electrostatic interactions between oppositely charged peptides and lipids can cause such effects (22). However, they are unlikely to be involved in the clavanin-PC interaction, as PC is zwitterionic and thus overall neutral. Nevertheless, we cannot exclude this positively because high concentrations of divalent and trivalent cations can cause an increase in phase transition temperature of DPPC (37) most likely by electrostatically interacting with the lipid phosphate group. Since clavanin is positively charged and localized in the interface, electrostatic interactions could be involved in the induction of higher DPPC-clavanin domains that melt at higher temperatures. However, very similar effects were observed at $\mathrm{pH} 7$ and 5.5. At this low $\mathrm{pH}$ the histidines are protonated, and the peptide is much more positively charged. Therefore, it is unlikely that electrostatic interactions between clavanin and the PC headgroup are solely responsible for the observed increased phase transition temperatures. Similar arguments exclude hydrogen bonding as a plausible cause for the observed effects. Another possibility would be headgroup dehydration; however, this is unlikely because the bilayers are embedded in a large excess of aqueous medium. Moreover, there are no precedents for peptide-induced headgroup dehydration. An obvious possibility is that the peptide could order the lipids and thereby stabilize the gel state. This is highly unlikely, given the results of the NMR study (see below).

This leaves as the most likely possibility that clavanin segregates together with some gel state lipids into a microdomain in which a peptide aggregate confines the lipid in the gel state. A similar effect was recently observed for dextran and partially hydrated PC bilayers in which the gel state was stabilized by confining stacks of bilayer within a dextran glass (36). Also, in the case of apolipoproteins a similar model was proposed for the effect that these proteins have on PC (37). To the best of our knowledge similar effects have not been observed for other antimicrobial peptides. This suggests that the clavanins with their unique composition, rich in histidines, glycines, and phenylalanines, have a special interaction with membranes. This view is further supported by the finding that substituting the five phenylalanine residues for tryptophans completely abolishes the occurrence of high-temperature transitions. Instead, the $5 \mathrm{~W}$ mutant gives rise to a more classical effect observed for hydrophobic peptides, i.e., a lowering of the phase transition.
The occurrence of more than one high-temperature transition at high clavanin concentrations suggests the occurrence of more than one supramolecular complex of clavanin and DPPC.

How can this effect on the DPPC gel-liquid-crystalline transition be understood in terms of the effects of clavanin on the lipid packing in both the gel and liquid-crystalline state?

In the liquid-crystalline phase the lipids become disordered over the entire length of the lipid molecule, as evidenced by the reduction of the residual chemical shift anisotropy in the ${ }^{31} \mathrm{P}$ NMR spectra and the reduced quadrupolar splitting of the chain deuterons of all lipid molecules. When the temperature is sufficiently high, the clavanin-gel state microdomain breaks up, and clavanin disperses throughout the bilayer and intercalates between all lipids, causing the reduced order. It is unlikely that clavanin adopts a transmembrane organization given the low $\alpha$-helical content of the membrane-associated peptide, as induced by its abundant Gly (12) and Phe (14) residues. Instead, a more interfacial, partially chain embedded location is more likely (12).

Under the gel state conditions clavanin also affects acyl chain packing. The ${ }^{2} \mathrm{H}$ NMR data demonstrate somewhat increased motional (probably rotational) freedom of at least part of the lipids. This shows the profound ability of clavanin to interact with membrane lipids. It suggests that the presence of clavanin (probably in an aggregate form) loosens up the gel state packing, but certainly not to the level of the liquidcrystalline phase, as the temperature over which the gel phase exists is even increased by the peptide.

The AFM analysis under gel state conditions visualizes the presence of substantial defects in the bilayer, which are very different from the characteristic striated domains observed for neutral transmembrane $\alpha$-helical peptides (24). Instead, they resemble to some extent the defects observed for positively charged transmembrane $\alpha$-helical peptides (29). The defects observed in those systems were proposed to originate from electrostatic repulsion between the peptides together with hemimicelle formation around peptide-lipid aggregates (29). We propose a similar organization of the clavanin-DPPC system in which clavanin aggregates border defects in the bilayer. These aggregates might be the same aggregates that stabilize the gel state.

In a sense the AFM images directly visualize the strong bilayer perturbing effect of clavanin and provide a picture of the aspecific carpet-like mechanism by which amphiphatic peptides destroy the membrane barrier.

The very similar effects of clavanin on DPPC observed at $\mathrm{pH} 7$ and 5.5 indicate that the interaction of clavanin with the membrane lipids is very similar under these conditions. This strongly suggests an interfacial localization of the majority of the peptides, as at $\mathrm{pH} 5.5$ the peptide carries a strong positive charge (12).

The implication of these findings for the $\mathrm{pH}$-dependent mode of action of clavanin is that the initial membrane interaction of the peptide is governed by clavanin-lipid interactions without much specificity. At low $\mathrm{pH}$, the charged histidines subsequently contribute to interactions with membrane proteins involved in proton translocation (13), resulting in a collapse of vital ion gradients and killing of the bacteria. 


\section{REFERENCES}

1. Lehrer, R. I., Lee, I. H., Menzel, L., Waring, A., and Zhao, C. (2001) Adv. Exp. Med. Biol. 484, 71-76.

2. Lee, I. H., Zhao, C., Cho, Y., Harwig, S. S. L., Cooper, E. L., and Lehrer, R. I. (1997) FEBS Lett., 158-162.

3. Zhao, C., Liaw, L., Lee, I. H., and Lehrer, R. I. (1997) FEBS Lett. 410, 490-492.

4. Epand, R. M., and Vogel, H. J. (1999) Biochim. Biophys. Acta $1462,11-28$.

5. Blondelle, S. E., Lohner, K., and Aguilar, M.-I. (1999) Biochim. Biophys. Acta 1462, 89-108.

6. Dathe, M., and Wieprecht, T. (1999) Biochim. Biophys. Acta 1462, 71-87.

7. Zasloff, M. (2002) Nature 415, 389-395.

8. Hancock, R. E. W., and Lehrer, R. (1998) Trends Biotechnol. 16, $82-88$.

9. Tossi, A., Sandri, L., and Giangaspero, A. (2000) Biopolymers $55,4-30$.

10. Van't Hof, W., Veerman, E. C. I., Helmerhorst, E., and Van Nieuw Amerongen, A. (2001) Biol. Chem. 382, 597-619.

11. Lee, I. H., Cho, Y., and Lehrer, R. I. (1997) Infect. Immun. 65 , 2898-2903.

12. Van Kan, E. J. M., Van der Bent, A., Demel, R. A., and De Kruijff, B. (2001) Biochemistry 40, 6398-6405.

13. Van Kan, E. J. M., Demel, R. A., Breukink, E., Van der Bent, A., and De Kruijff, B. (2002) Biochemistry 41, 7529-7539.

14. Van Kan, E. J. M., Demel, R. A., Van der Bent, A., and De Kruijff, B. (2003) Biochim. Biophys. Acta 1615, 84-92.

15. Bechinger, B. (1996) J. Mol. Biol. 263, 768-775.

16. Vogt, T. C. B., and Bechinger, B. (1999) J. Biol. Chem. 274 , 29115-29121.

17. Fresta, M., Ricci, M., Rossi, C., Furneri, P. M., and Puglisi, G. (2000) J. Colloid Interface Sci. 226, 222-230.

18. Prenner, E. J., Lewis, R. N. A. H., Neuman, K. C., Gruner, S. M., Kondejewski, L. H., Hodges, R. S., and McElhaney, R. N. (1997) Biochemistry 36, 7909-7916.

19. Prenner, E. J., Lewis, R. N. A. H., and McElhaney, R. N. (1999) Biochim. Biophys. Acta 1462, 201-221.

20. Lohner, K., and Prenner, E. J. (1999) Biochim. Biophys. Acta 1462, $141-156$
21. Lohner, K., Staudegger, E., Prenner, E. J., Lewis, R. N. A. H., Kriechbaum, M., Degovics, G., and McElhaney, R. N. (1999) Biochemistry 38, 16514-16528.

22. Lohner, K., Latal, A., Lehrer, R. I., and Ganz, T. (1997) Biochemistry 36, 1525-1531.

23. Rouser, G., Fleischer, S., and Yamamoto, A. (1970) Lipids 5, 494496.

24. Rinia, H. A., Kik, R. A., Demel, R. A., Snel, M. M. E., Killian, J. A., Van der Eerden, J. P. J. M., and De Kruijff, B. (2000) Biochemistry 39, 5852-5858.

25. Davis, J. A., Jeffrey, K. R., Bloom, M., Valic, M. I., and Higgs, T. P. (1976) Chem. Phys. Lett. 42, 390-394.

26. Brian, A. A., and McConnell, H. M. (1984) Proc. Natl. Acad. Sci. U.S.A. 81, 6159-6163.

27. Morein, S., Killian, J. A., and Sperotto, M. M. (2002) Biophys. J. 82, 1405-1417.

28. Paré, C., Lafleur, M., Liu, F., Lewis, R. N. A. H., and McElhaney, R. N. (2001) Biochim. Biophys. Acta 1511, 60-73.

29. Rinia, H. A., Boots, J.-W. P., Rijkers, D. T. S., Kik, R. A., Snel, M. M. E., Demel, R. A., Killian, J. A., Van der Eerden, J. P. J. M., and De Kruijff, B. (2002) Biochemistry 41, 2814-2824.

30. Seelig, J. (1978) Biochim. Biophys. Acta 515, 105-140.

31. Cullis, P. R., and De Kruijff, B. (1979) Biochim. Biophys. Acta 559, 399-420.

32. Davis, J. H. (1983) Biochim. Biophys. Acta 737, 117-171.

33. Huang, T. H., Skarjune, R. P., Wittebort, R. J., Griffin, R. G., and Oldfield, E. (1980) J. Am. Chem. Soc. 102, 7377-7379.

34. Tamm, L. K., and Shao, Z. (1998) in Biomembrane structures (Harris, P. I., and Chapman, D., Eds.) pp 169-185, IOS Press, Amsterdam.

35. Mou, J., Czajkowsky, D. M., and Shao, Z. (1996) Biochemistry $35,3222-3226$.

36. Vereyken, I. J., Chupin, V., Hoekstra, F. A., Smeekens, C. M., and De Kruijff, B. (2003) Biophys. J. (in press).

37. Simon, S. A., Lis, L. J., Kaufman, J. W., and MacDonald, R. C. (1975) Biochim. Biophys. Acta 375, 317-326.

BI0349017 